\title{
Isotope Labeling Reveals Fast Atomic and Molecular Exchange in Mechanochemical Milling Reactions
}

\author{
Stipe Lukin, ${ }^{\dagger}$ Martina Tireli, ${ }^{\dagger}$ Tomislav Stolar, ${ }^{\dagger}$ Dajana Barišić, ${ }^{\dagger}$ Maria Valeria Blanco, ${ }^{\ddagger}$ \\ Marco di Michiel, ${ }^{\ddagger}$ Krunoslav Užarević, ${ }^{\dagger}$ and Ivan Halasz ${ }^{*, \dagger}$ \\ $\dagger$ †ivision of Physical Chemistry, Ruđer Bošković Institute, Bijenička 54, 10000 Zagreb, Croatia \\ $\ddagger E S R F$ - the European Synchrotron, 71 Avenue des Martyrs, 38000 Grenoble, France \\ Received December 11, 2020; E-mail: ivan.halasz@irb.hr
}

\begin{abstract}
Using tandem in situ monitoring and isotope-labeled solids, we reveal that mechanochemical ball-milling overcomes inherently slow solid-state diffusion through continuous comminution and growth of milled particles. This process occurs with or without a net chemical reaction and also occurs between solids and liquid additives which can be practically used for highly efficient deuterium labeling of solids. The presented findings reveal a fundamental aspect of milling reactions and also delineate a methodology that should be considered in the study of mechanochemical reaction mechanisms.
\end{abstract}

Ball milling exerts mechanical energy through compression, shearing, and friction to a solid reaction mixture, thus coercing materials and molecules to react. ${ }^{1}$ Early theories of such mechanochemical reactions assumed short and localized, but extreme conditions of highly-elevated temperature and pressure achieved at the spots of milling ball impacts, providing conditions to overcome the high energy barrier of a solid-state reaction. ${ }^{2-5}$ However, with extension of milling to soft materials, ${ }^{6-8}$ a different view on mechanochemical reactivity is emerging ${ }^{9-12}$ where mechanochemical reactions are recognized to exhibit solution-like kinetics, ${ }^{13}$ intermediates, ${ }^{14,15}$ remarkable selectivity ${ }^{16-18}$ strong temperature dependence, ${ }^{10,19}$ and can be quite fast. ${ }^{20,21}$ These features indicate that extremely slow diffusion in crystalline solids ${ }^{22-24}$ may be overcome by milling.

We thus hypothesized that molecular or atomic migrations among crystallites should be possible through surface contacts between milled solid particles, even without a net chemical reaction. In this work, to address this fundamental aspect of mechanochemical milling, we have applied tandem in situ monitoring ${ }^{25,26}$ to milling of isotope-labeled solids and show that milling results in fast exchange of atoms and molecules between crystallites, thus creating a reaction environment that is not restrained by slow solid-state diffusion. Molecular and atomic exchange occurs both when new phases are formed during milling, but also between milled solids which are non-reactive, and extends to milling of solids with liquid additives.

First, we study milling of benzoic acid (ba) and 2-pyridone (pyo) wherein a 1:1 cocrystal (bapyo) is formed (Scheme 1). Both ba and pyo bear one exchangeable hydrogen atom: the hydrogen of the carboxylate group of ba and the pyridinium hydrogen of pyo. Cocrystal formation requires no net transfer of hydrogen atoms as would be the case for example, with salt formation, but any $\mathrm{H} / \mathrm{D}$ exchange will influence energies of molecular vibrations. We have performed experiments where neither ba nor pyo were deuterated, where either ba or pyo were deuterated (ba-d and pyo-d, respectively), and
Scheme 1. Cocrystal formation between ba and pyo. Exchangeable hydrogen atoms of ba, pyo, and bapyo are denoted as H/D.

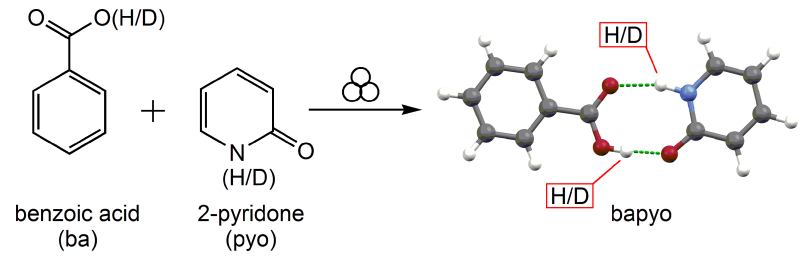

where both ba and pyo were deuterated. In all, cocrystal formation proceeds directly from reactants (Figs. S1-S5) and without amorphization (Figs. S6 and S7). ${ }^{27}$ In experiments $\mathrm{ba}+$ pyo and ba-d + pyo-d no isotope exchange could be detected since all exchangeable hydrogen atoms are of the same isotope. On the other hand, in experiments where either ba or pyo were deuterated, $\mathrm{H} / \mathrm{D}$ exchange is possible. That is, ba-d could potentially transfer its deuteron to pyo and vice versa, pyo-d could transfer its deuteron to ba. These two experiments resulted with essentially the same Raman spectra after 25 min milling (Figs. 1, S8, S9), indicating the same isotope distribution between ba and pyo molecules in the product cocrystal.

Figure 1 depicts the most characteristic bands to assess $\mathrm{H} / \mathrm{D}$ exchange in time-resolved Raman spectra. Vibration band of carboxylate group bending is found at $793 \mathrm{~cm}^{-1}$ for ba and at $765 \mathrm{~cm}^{-1}$ for ba-d (S31). For bapyo-hh, the same vibration of benzoic acid is now at $800 \mathrm{~cm}^{-1}$, while it is at $774 \mathrm{~cm}^{-1}$ in bapyo-dd. Since this is dominantly a vibration of the benzoic acid moiety, also in the cocrystal, we use it to assess its deuteration state. In the ba-d + pyo experiment the band at $765 \mathrm{~cm}^{-1}$ diminishes, while the band at $774 \mathrm{~cm}^{-1}$ increases in intensity as ba-d becomes incorporated in the cocrystal. Importantly, the band at $774 \mathrm{~cm}^{-1}$ reaches ca. half the intensity as in the fully deuterated bapyo-dd indicating that ca. half of deuterons were transferred from ba-d to pyo in the bapyo-dh cocrystal. Switching the deuteron label in the ba + pyo-d experiment, the band at $774 \mathrm{~cm}^{-1}$ also increases in intensity, which can only be due to deuteron transfer from pyo-d to ba, and reaches the same intensity as in the previous ba-d + pyo experiment. Potential deuteron transfer from pyo-d to ba, but without cocrystal formation should have been indicated by the emergence of the pure ba-d band at $765 \mathrm{~cm}^{-1}$, which we do not observe. 

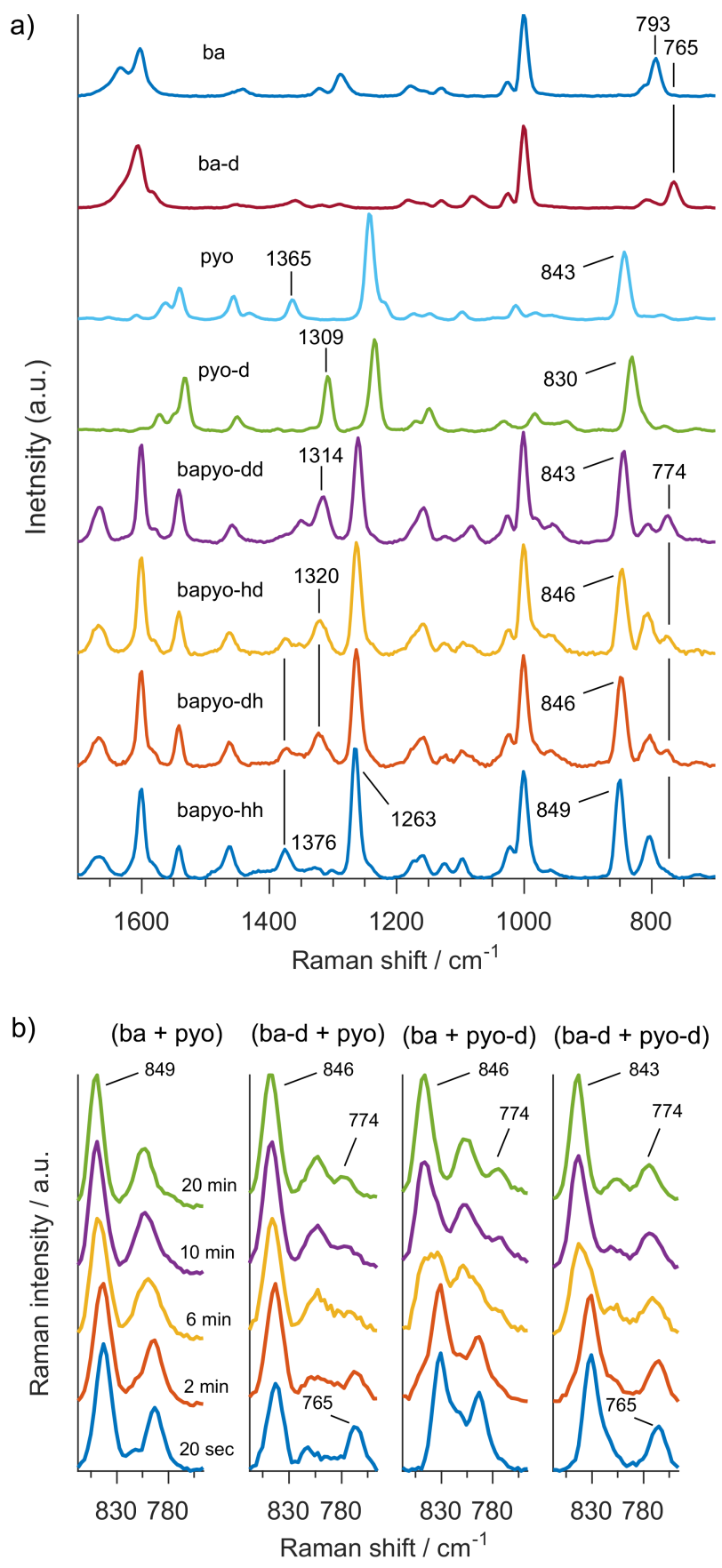

Figure 1. (a) Raman spectra of natural and deuterated reactants and final Raman spectra of variously deuterated cocrystals obtained after 25 min milling. Labeling: bapyo-xx, $(\mathrm{x}=\mathrm{h}$ or $\mathrm{d})$ corresponds to deuteration of starting reactants, e.g. bapyo-hd designates the product of the reaction ba + pyo-d. (b) Timeresolved characteristic section of Raman spectra during milling at room temperature.

$\mathrm{NH}$ rocking vibration band is at $1365 \mathrm{~cm}^{-1}$ for pyo and at $1309 \mathrm{~cm}^{-1}$ for pyo-d. This band in the bapyo-hh cocrystal is found at $1376^{-1}$ and at $1314 \mathrm{~cm}^{-1}$ for bapyo-dd. Products in ba + pyo-d and ba-d + pyo experiments exhibit bands at 1320 and $1376 \mathrm{~cm}^{-1}$ of similar intensities, again as a consequence of $\mathrm{H} / \mathrm{D}$ exchange and indicate equal deuteron distribution between ba and pyo moieties in the cocrystal.

To further explore the fast exchange of hydrogen atoms during milling, we have milled the 1:1 mixture of ba and paracetamol (prc, also known as acetaminophen), which remains a physical mixture (Figs. S12-S15). Lack of experi-
Scheme 2. Milling of ba and prc produces no net chemical change. Exchangeable hydrogen atoms of ba and prc are denoted.

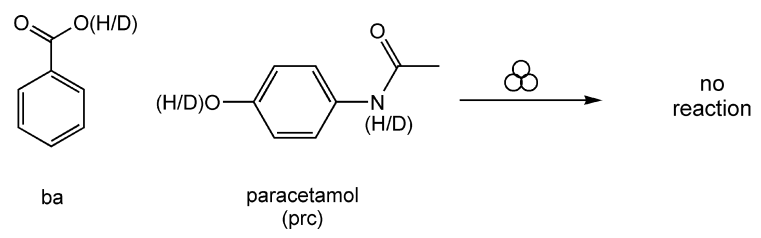

mental evidence for the formation of the cocrystal between these two compounds agrees with first principle calculations where the most stable predicted cocrystal was found to be thermodynamically unfavorable relative to reactants. ${ }^{28}$ Here, H/D exchange in the bulk could be enabled only through fast formation of new contact surfaces between crystallites of ba and prc, as a consequence of mixing and continuous particle comminution and growth. ${ }^{29,30}$ While particle comminution results from milling ball impacts, growth of crystalline nanoparticles is here evident from a stable average particle size of both ba and prc (Fig. 2, S16)
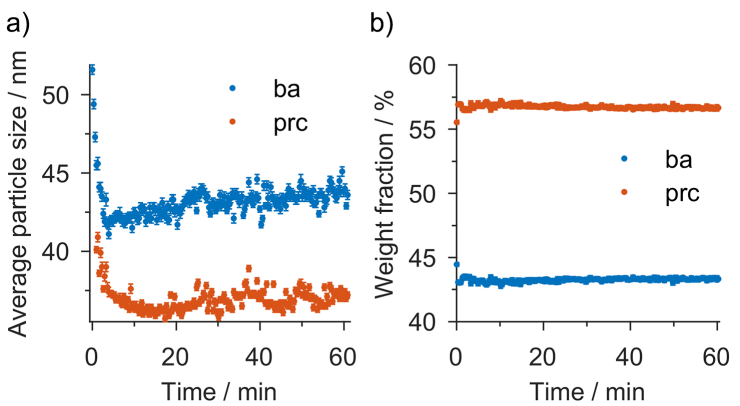

Figure 2. (a) Average particle size of ba and prc and b) weight fractions of ba and prc during milling derived from in situ PXRD data.

In situ Raman monitoring of milling where either ba or prc were deuterated revealed changes in intensities of bands corresponding to vibrations that are affected by $\mathrm{H} / \mathrm{D}$ exchange. Milling ba + prc- $\mathrm{d}_{2}$ decreases intensity of the ba band at $793 \mathrm{~cm}^{-1}$ and increases intensity of the band at $765 \mathrm{~cm}^{-1}$, as a result of deuteron transfer from prc- $\mathrm{d}_{2}$ to ba and partial formation of ba-d (Fig 3). Alternatively, milling of ba-d + prc increases the band at $793 \mathrm{~cm}^{-1}$ of ba and simultaneously decreases the band at $765 \mathrm{~cm}^{-1}$ of ba-d. Band of prc at $796 \mathrm{~cm}^{-1}$ is shifted to $782 \mathrm{~cm}^{-1}$ upon deuteration, without a change in intensity (Fig 3 ).

For comparison, milling of ba + prc and ba-d + prc- $_{2}$ exhibited no changes in both PXRD and Raman in situ monitoring (Figs. S12 and S13). Thus, H/D exchange in milling reactions cannot be merely a consequence of a parallel chemical reaction, but is inherent to the milling process itself indicating also that a thermodynamic equilibrium between solids is readily achieved during milling, in accordance with previously described equilibration of solids, ${ }^{31}$ as well polymorph selectivity through particle size reduction ${ }^{29}$ or solvation of nanoparticles. ${ }^{32,33}$ To exclude the possibility of $\mathrm{H} / \mathrm{D}$ exchange being facilitated by moisture due to samples being prepared in air, ${ }^{34}$ we have milled ba-d + prc where the sample was prepared in a glovebox in an argon atmosphere. The same H/D exchange was observed here as in experiments where samples were prepared in air (Fig S17). 


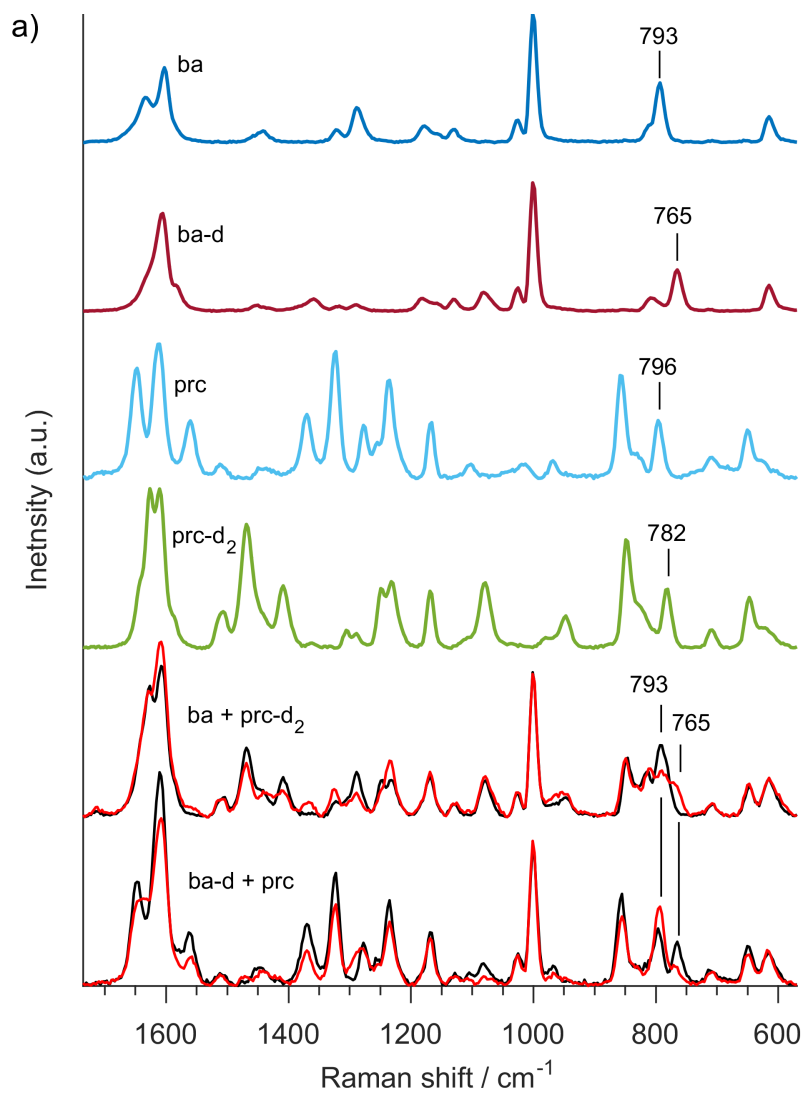

b)

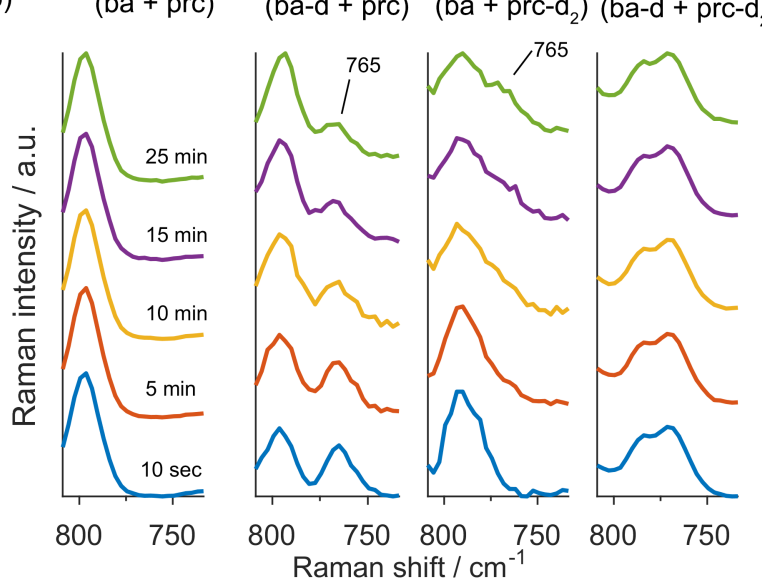

Figure 3. (a) Raman spectra of natural and deuterated ba and prc and first and final Raman spectra for experiments ba + prc$\mathrm{d}_{2}$ and ba-d + prc. Color code: black - first spectrum, red - last spectrum after 45 min milling. Since prc bears two exchangeable protons and ba bears one, $\mathrm{H} / \mathrm{D}$ ratio of exchangeable hydrogens is $1: 2$ for the ba + prc- $\mathrm{d}_{2}$ experiment and $2: 1$ for milling ba-d + prc, resulting in different final spectra in these two experiments. (b) Time-resolved characteristic section of Raman spectra during milling.

Despite recent advances, ${ }^{10,35,36}$ temperature control in milling is currently not widely established, ${ }^{37,38}$ which may be troublesome since milling is generally self-heating. ${ }^{39,40} \mathrm{In}$ our milling setup the temperature has gradually risen from the starting room temperature to ca. $35{ }^{\circ} \mathrm{C}$ (Fig. S26). Since H/D exchange involves breaking of chemical bonds, which must be associated with an energy barrier, its rate should depend on temperature. ${ }^{10}$ We have thus explored $\mathrm{H} / \mathrm{D}$ exchange at low temperature around nitrogen liquefaction and at $50{ }^{\circ} \mathrm{C}$ (Figs. S27-S30). While cocrystal forma- tion was faster at $50{ }^{\circ} \mathrm{C}$, it was incomplete at low temperature. Overall, we have observed the same H/D exchange as for milling in ambient conditions (Fig. S21). H/D exchange in the ba + prc system resulted in a slower $\mathrm{H} / \mathrm{D}$ exchange at low temperature, but was comparable for milling at $50{ }^{\circ} \mathrm{C}$ and milling started from room temperature.

We extend $\mathrm{H} / \mathrm{D}$ exchange to liquid-assisted grinding (LAG) ${ }^{41-43}$ where we have milled ba with $\mathrm{D}_{2} \mathrm{O}$ in the $1: 1$ stoichiometric ratio. Deuteration of ba, which is poorly soluble in water at room temperature, could be readily observed with an increase in intensity of the ba-d band at $765 \mathrm{~cm}^{-1}$ as deuteron is transfered from $\mathrm{D}_{2} \mathrm{O}$ to ba and a corresponding decrease in intensity of the $793 \mathrm{~cm}^{-1}$ band belonging to ba. (Fig. 4). On the $2 \mathrm{mmol}$ scale, $\mathrm{H} / \mathrm{D}$ exchange reached equilbrium after about $30 \mathrm{~min}$ milling with the spectrum consistent with a distribution of $2 / 3$ of deuterium atoms on ba. This confirms that $\mathrm{D}_{2} \mathrm{O}$ interacted chemically with milled ba and indicates that poor solid's solubility in the added liquid is not an obstacle for such an interaction, in accordance with previous observations of the role of water in grinding. ${ }^{43}$

Efficient deuteration of ba inspired us to use LAG for preparatory deuterium labeling, similar to a milling approach that has recently been applied to enrich samples with ${ }^{17} \mathrm{O} .{ }^{44}$ Here, we have been able to deuterate $2 \mathrm{mmol}$ of ba at room temperature by three-times milling with $4 \mathrm{mmol}$ of $\mathrm{D}_{2} \mathrm{O}$ and drying of the solid in between. In total we have used only $216 \mu \mathrm{L}$ of $\mathrm{D}_{2} \mathrm{O}$ to achieve almost full deuteration of $244 \mathrm{mg}$ of ba, which amounts to at least 60 -fold solvent reduction as compared to solution deuteration (see Supporting Information) and no loss of the deuterated solid.

a)
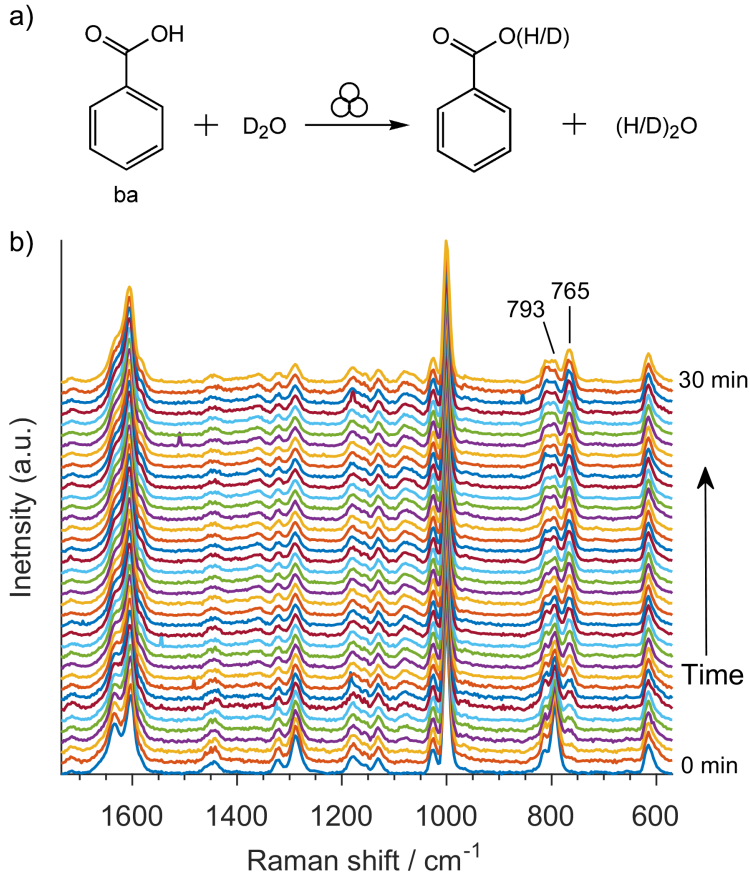

Figure 4. a) scheme shows exchangeable atoms for LAG reaction with $\mathrm{D}_{2} \mathrm{O}$. b) stacked time-resolved Raman spectra for milling of ba with $\mathrm{D}_{2} \mathrm{O}$ as a liquid additive in the 1:1 stoichiometric ratio. Spectra of pure ba and ba-d are given in Fig. 1

Finally, we show whole-molecule exchange by milling ba and ${ }^{13}$ C-labeled ba (ba*, Fig. 5). PXRD monitoring showed no phase transformations while Raman monitoring revealed fast changes consistent with the formation of the baba* heterodimer. Figure 5 represents Raman and FTIR-ATR 
a)<smiles>O=C(O)c1cccc(C(=O)OC(=O)c2ccccc2)c1</smiles>
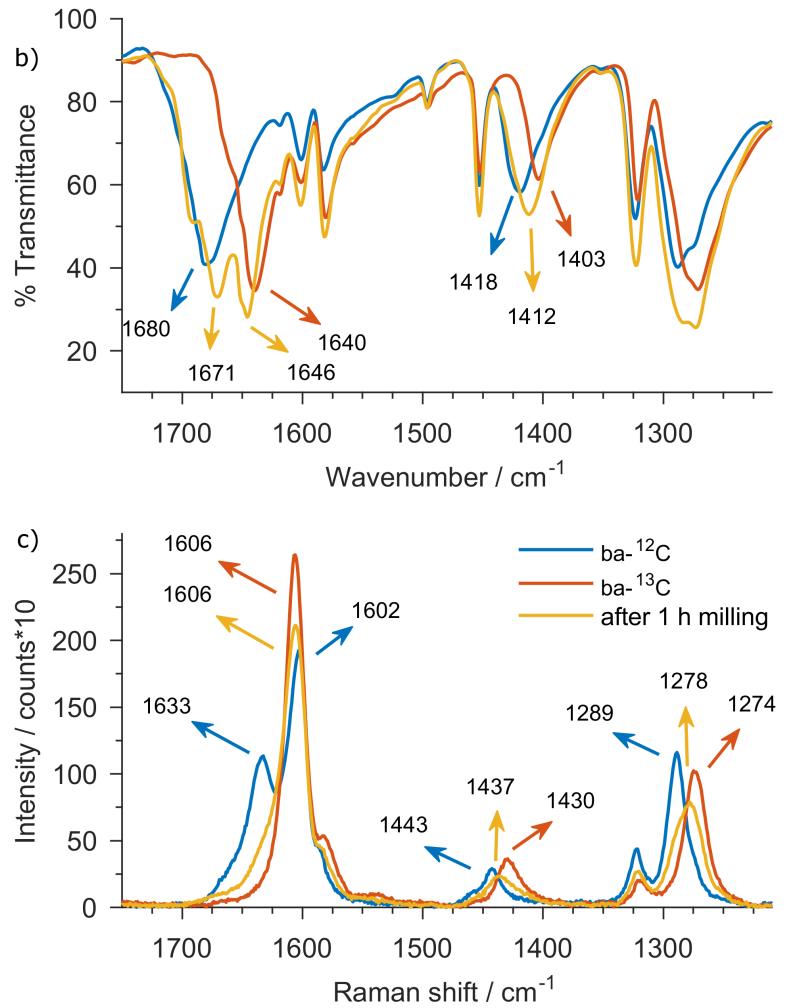

Figure 5. a) Formation of the heterodimer between ba and benzoic acid labeled with a ${ }^{13} \mathrm{C}$ atom $\left(\mathrm{ba}^{*}\right)$. Labeling position denoted with '*'. b) FTIR-ATR spectra and c) Raman spectra of the natural and labeled ba and their 1:1 reaction mixture obtained after one hour milling. Spectral resolution is $1 \mathrm{~cm}^{-1}$.

spectra of ba and ba* and their 1:1 mixture after one hour milling. The $\mathrm{O}=\mathrm{C}-\mathrm{O}$ asymmetric stretching at $1437 \mathrm{~cm}^{-1}$ is found between the band for pure ba and pure ba*. Similarly, $\mathrm{C}-\mathrm{C}-\mathrm{OH}$ asymmetric stretching at $1278 \mathrm{~cm}^{-1}$ for the milled mixture is between the corresponding bands for ba and ba*. Calculations in the gas phase confirm that the baba* heterodimer will exhibit bands between the corresponding bands for the two homodimers (Figs. 5, ??, ??). Observed band shifts in ATR spectra similarly indicate formation of the baba* heterodimer.

In conclusion, milled crystalline solids rapidly exchange hydrogen atoms and whole molecules, with or without a net chemical reaction. Through continuous particle comminution and growth during milling, the whole of milled solid particles thus becomes accessible to the surface, to other milled particles and also to any liquid present, thus overcoming the otherwise slow solid-state diffusion. We expect the presented methodology of using isotope-labeled solids together with in situ monitoring will become an indispensable tool to study mechanochemical reaction mechanisms not only on the level of molecular transformations via kinetic isotope effects, ${ }^{45,46}$ but also on the level of bulk solids.

Acknowledgement We are grateful to Dejan-Krešimir
Bučar for critically reading the manuscript, to Nikola Biliškov and Igor Milanović for their help with the use of a glovebox, the team at the fine-mechanics workshop of the Ruđer Bošković Institute and Nikola Cindro, Edi Topić and Mirta Rubčić for their help with collecting a DSC thermogram. We are also grateful to the Reviewers whose comments and careful reading improved this manuscript. Computations were done on the Isabella cluster at SRCE, Zagreb. Financial support from the Croatian Science Foundation (Grant No. 4744) and the Adris foundation is gratefully acknowledged. SL is supported by the Croatian Science Foundation.

\section{Supporting Information Avail- able}

Experimental, tandem in situ Raman and PXRD plots, Rietveld-extracted reaction profiles, temperature profiles, computational details.

\section{References}

(1) Do, J.-L.; Friščić, T. Mechanochemistry: A Force of Synthesis ACS Cent. Sci. 2017, 3, 13-19.

(2) Urakaev, F.; Boldyrev, V. Mechanism and kinetics of mechanochemical processes in comminuting devices: 2. Applications of the theory. Experiment. Powder Technol. 2000, 107, $197-206$.

(3) Fernández-Bertran, J. Mechanochemistry: An overview. Pure Appl. Chem. 1999, 71, 581-586.

(4) Jones, W.; Eddleston, M. D. Introductory Lecture Mechanochemistry, a versatile synthesis strategy for new materials. Faraday Discuss. 2014, 170, 9-34.

(5) Baláž, P.; Achimovičová, M.; Baláž, M.; Billik, P.; CherkezovaZheleva, Z.; Criado, J. M.; Delogu, F.; Dutková, E.; Gaffet, E.; Gotor, F. J.; Kumar, R.; Mitov, I.; Rojac, T. Senna, M.; Streletskii, A.; Wieczorek-Ciurowa, K. Hallmarks of mechanochemistry: from nanoparticles to technology. Chem. Soc. Rev. 2013, 42, 7571-7637.

(6) James, S. L.; Adams, C. J.; Bolm, C.; Braga, D.; Collier, P. Friščić, T.; Grepioni, F.; Harris, K. D. M.; Hyett, G.; Jones, W. Krebs, A.; Mack, J.; Maini, L.; Orpen, A. G.; Parkin, I. P. Shearouse, W. C.; Steed, J. W.; Waddell, D. C. Mechanochemistry: opportunities for new and cleaner synthesis. Chem. Soc. Rev. 2012, 41, 413-447.

(7) Braga, D.; Maini, L.; Grepioni, F. Mechanochemical preparation of co-crystals. Chem. Soc. Rev. 2013, 42, 7638-7648.

(8) Do, J.-L.; Friščić, T. Chemistry 2.0: Developing a New, SolventFree System of Chemical Synthesis Based on Mechanochemistry. Synlett 2017, 28, 2066-2092.

(9) Takacs, L. What is unique about mechanochemical reactions? Acta Phys. Pol. A 2014, 126, 1040-1043.

(10) Andersen, J. M.; Mack, J. Decoupling the Arrhenius equation via mechanochemistry. Chem. Sci. 2017, 8, 5447-5453.

(11) Friščić, T.; Jones, W. Recent Advances in Understanding the Mechanism of Cocrystal Formation via Grinding. Cryst. Growth Des. 2009, 9, 1621-1637.

(12) Boldyreva, E. Mechanochemistry of inorganic and organic systems: what is similar, what is different? Chem. Soc. Rev. 2013 42, 7719-7738.

(13) Ma, X.; Yuan, W.; Bell, S. E. J.; James, S. L. Better understanding of mechanochemical reactions: Raman monitoring reveals surprisingly simple 'pseudo-fluid' model for a ball milling reaction. Chem. Commun. 2014, 50, 1585-1587.

(14) Katsenis, A. D.; Puškarić, A.; Štrukil, V.; Mottillo, C.; Julien, P. A.; Užarević, M. H., K. Pham; Do, T. O.; Kimber, S. A. J.; Lazić, P.; Magdysyuk, O.; Dinnebier, R. E.; Halasz, I. Friščić, T. Nat. Commun. 2015, 6, 6662 .

(15) Kulla, H.; Greiser, S.; Benemann, S.; Rademann, K.; Emmerling, F. Knowing When To Stop - Trapping Metastable Polymorphs in Mechanochemical Reactions. Cryst. Growth Des. 2017, 17, 1190-1196

(16) Trask, A. V.; Shan, N.; Motherwell, W. D. S.; Jones, W. Feng, S.; Tan, R. B. H.; Carpenter, K. J. Selective polymorph transformation via solvent-drop grinding. Chem. Commun. 2005, 880-882.

(17) Lukin, S.; Lončarić, I.; Tireli, M.; Stolar, T.; Blanco, M. V.; Lazić, P.; Užarević, K.; Halasz, I. Experimental and Theoretical Study of Selectivity in Mechanochemical Cocrystallization of Nicotinamide with Anthranilic and Salicylic Acid. Cryst. Growth Des. 2018, 18, 1539-1547. 
(18) Fischer, F.; Lubjuhn, D.; Greiser, S.; Rademann, K.; Emmerling, F. Supply and Demand in the Ball Mill: Competitive Cocrystal Reactions. Cryst. Growth Des. 2016, 16, 5843-5851.

(19) Užarević, K.; Štrukil, V.; Mottillo, C.; Julien, P. A. Puškarić, A.; Friščić, T.; Halasz, I. Exploring the Effect of Temperature on a Mechanochemical Reaction by in Situ Synchrotron Powder X-ray Diffraction. Cryst. Growth Des. 2016, 16, 23422347.

(20) Friščić, T.; Halasz, I.; Beldon, P. A.; Belenguer, A. M. Adams, F.; Kimber, S. A. J.; Honkimäki, V.; Dinnebier, R. E. Real-time and in situ monitoring of mechanochemical milling reactions. Nature Chem. 2013, 5, 66-73.

(21) Halasz, I.; Puškarić, A.; Kimber, S. A. J.; Beldon, P. J.; Belenguer, A. M.; Adams, F.; Honkimäki, V.; Dinnebier, R. E.; Patel, B.; Jones, W.; Štrukil, V.; Friščić, T. Real-Time In Situ Powder X-ray Diffraction Monitoring of Mechanochemical Synthesis of Pharmaceutical Cocrystals. Angew. Chem. Int. Ed. 2013, 52, 11538-11541.

(22) Chezeau, J.; Strange, J. Diffusion in molecular crystals. Physics Reports 1979, 53, $1-92$.

(23) Borgschulte, A.; Gremaud, R.; Lodziana, Z.; Züttel, A. Hydrogen tracer diffusion in $\mathrm{LiBH}_{4}$ measured by spatially resolved Raman spectroscopy. Phys. Chem. Chem. Phys. 2010, 12, 50615066 .

(24) Borgschulte, A.; Züttel, A.; Hug, P.; Racu, A.-M.; Schoenes, J. Hydrogen-Deuterium Exchange in Bulk LiBH 4 . J. Phys. Chem. A 2008, 112, 4749-4753.

(25) Batzdorf, L.; Fischer, F.; Wilke, M.; Wenzel, K.-J. r.; Emmerling, F. Direct In Situ Investigation of Milling Reactions Using Combined X-ray Diffraction and Raman Spectroscopy. Angew. Chem. Int. Ed. 2015, 54, 1799-1802.

(26) Lukin, S.; Stolar, T.; Tireli, M.; Blanco, M. V.; Babić, D. Friščić, T.; Užarević, K.; Halasz, I. Tandem In Situ Monitoring for Quantitative Assessment of Mechanochemical Reactions Involving Structurally Unknown Phases. Chem. Eur. J. 2017, 23, 13941-13949.

(27) Halasz, I.; Friščić, T.; Kimber, S. A. J.; Užarević, K.; Puškarić, A.; Mottillo, C.; Julien, P.; Štrukil, V.; Honkimäki, V.; Dinnebier, R. E. Quantitative in situ and real-time monitoring of mechanochemical reactions. Faraday Discuss. 2014, 170, 203-221.

(28) Chan, H. C. S.; Kendrick, J.; Neumann, M. A.; Leusen, F J. J. Towards ab initio screening of co-crystal formation through lattice energy calculations and crystal structure prediction of nicotinamide, isonicotinamide, picolinamide and paracetamol multi-component crystals. CrystEngComm 2013, 15, 37993807 .

(29) Willart, J.-F.; Lefebvre, J.; Danède, F.; Comini, S.; Looten, P.; Descamps, M. Polymorphic transformation of the $\Gamma$-form of $\mathrm{d}-$ sorbitol upon milling: structural and nanostructural analyses. Solid State Commun. 2005, 135, 519 - 524.

(30) Belenguer, A. M.; Lampronti, G. I.; De Mitri, N.; Driver, M. Hunter, C. A.; Sanders, J. K. M. Understanding the Influence of Surface Solvation and Structure on Polymorph Stability: A Combined Mechanochemical and Theoretical Approach. J. Am. Chem. Soc. 2018, 140, 17051-17059.

(31) Belenguer, A. M.; Friščić, T.; Day, G. M.; Sanders, J. K. M Solid-state dynamic combinatorial chemistry: reversibility and thermodynamic product selection in covalent mechanosynthesis. Chem. Sci. 2011, 2, 696-700.

(32) Belenguer, A. M.; Lampronti, G. I.; Cruz-Cabeza, A. J.; Hunter, C. A.; Sanders, J. K. M. Solvation and surface effects on polymorph stabilities at the nanoscale. Chem. Sci. 2016, 7 , $6617-6627$

(33) Belenguer, A. M. Lampronti, G. I. Wales, D J ; Sanders, J. K. M. Direct Observation of Intermediates in a Thermodynamically Controlled Solid-State Dynamic Covalent Reaction. J. Am. Chem. Soc. 2014, 136, 16156-16166.

(34) Cinčić, D.; Brekalo, I.; Kaitner, B. Effect of atmosphere on solidstate amine-aldehyde condensations: gas-phase catalysts for solid-state transformations. Chem. Commun. 2012, 48, 1168311685.

(35) Fischer, F.; Wenzel, K.-J.; Rademann, K.; Emmerling, F. Quantitative determination of activation energies in mechanochemical reactions. Phys. Chem. Chem. Phys. 2016, 18, 2332023325.

(36) Andersen, J.; Mack, J. Insights into Mechanochemical Reactions at Targetable and Stable, Sub-ambient Temperatures. Angew. Chem. Int. Ed. 2018, 57, 13062-13065.

(37) Crawford, D. E.; Miskimmin, C. K. G.; Albadarin, A. B. Walker, G.; James, S. L. Organic synthesis by Twin Screw Extrusion (TSE): continuous, scalable and solvent-free. Green Chem. 2017, 19, 1507-1518.

(38) Andersen, J.; Mack, J. Mechanochemistry and organic synthesis: from mystical to practical. Green Chem. 2018, 20, 1435-1443.

(39) Užarević, K.; Ferdelji, N.; Mrla, T.; Julien, P. A.; Halasz, B.; Friščić, T.; Halasz, I. Enthalpy vs. friction: heat flow modelling of unexpected temperature profiles in mechanochemistry of metal-organic frameworks. Chem. Sci. 2018, 9, 2525-2532.

(40) Kulla, H.; Wilke, M.; Fischer, F.; Röllig, M.; Maierhofer, C. Emmerling, F. Warming up for mechanosynthesis - temperature development in ball mills during synthesis. Chem. Commun. 2017, 53, 1664-1667.
(41) Shan, N.; Toda, F.; Jones, W. Mechanochemistry and co-crystal formation: effect of solvent on reaction kinetics. Chem. Commun. 2002, 2372-2373.

(42) Friščić, T.; Childs, S. L.; Rizvi, S. A. A.; Jones, W. The role of solvent in mechanochemical and sonochemical cocrystal formation: a solubility-based approach for predicting cocrystallisation outcome. CrystEngComm 2009, 11, 418-426.

(43) Losev, E.; Boldyreva, E. The role of a liquid in "dry" cogrinding: A case study of the effect of water on mechanochemical synthesis in a "L-serine-oxalic acid" system. CrystEngComm 2014, 16, 3857-3866.

(44) Métro, T.-X.; Gervais, C.; Martinez, A.; Bonhomme, C.; Laurencin, D. Unleashing the Potential of ${ }^{17} \mathrm{O}$ NMR Spectroscopy Using Mechanochemistry. Angew. Chem. Int. Ed. 2017, 56 , 6803-6807.

(45) Hermann, G. N.; Becker, P. Bolm, C. Mechanochemica Rhodium(III)-Catalyzed $\mathrm{C}-\mathrm{H}$ Bond Functionalization of Acetanilides under Solventless Conditions in a Ball Mill. Angew. Chem. Int. Ed. 2015, 54, 7414-7417.

(46) Hermann, G. N.; Becker, P.; Bolm, C. Mechanochemical Iridium(III)-Catalyzed $\mathrm{C}-\mathrm{H}$ Bond Amidation of Benzamides with Sulfonyl Azides under Solvent-Free Conditions in a Ball Mill. Angew. Chem. Int. Ed. 2016, 55, 3781-3784. 